\title{
Memory Consolidation of Auditory Pavlovian Fear Conditioning Requires Protein Synthesis and Protein Kinase A in the Amygdala
}

\author{
Glenn E. Schafe and Joseph E. LeDoux \\ W. M. Keck Foundation Laboratory of Neurobiology, Center for Neural Science, New York University, New York, \\ New York, 10003
}

Previous studies have shown that long-term potentiation (LTP) can be induced in the lateral nucleus of the amygdala (LA) after stimulation of central auditory pathways and that auditory fear conditioning modifies neural activity in the LA in a manner similar to LTP. The present experiments examined whether intra-LA administration of inhibitors of protein synthesis or protein kinase A (PKA) activity, treatments that block LTP in hippocampus, interfere with memory consolidation of fear conditioning. In the first series of experiments, rats received a single conditioning trial followed immediately by intra-LA infusions of anisomycin (a protein synthesis inhibitor) or Rp-cAMPS (an inhibitor of PKA activity) and were tested $24 \mathrm{hr}$ later. Results

Considerable progress has been made in identifying the neuroanatomical and cellular events underlying Pavlovian fear conditioning, particularly auditory fear conditioning, which is thought to involve alterations in synaptic transmission in the lateral nucleus of the amygdala (LA) (Davis, 1997; Fanselow and LeDoux, 1999; LeDoux, 2000). Less is known, however, about the molecular mechanisms that underlie fear memory consolidation. It is thus of interest that long-term potentiation (LTP), the leading cellular model of memory consolidation in the mammalian brain, has been demonstrated in the LA both in vivo and in vitro after stimulation of central auditory pathways (Chapman et al., 1990; Clugnet and LeDoux, 1990; Rogan and LeDoux, 1995; Huang and Kandel, 1998; Weisskopf et al., 1999). Furthermore, neural activity in the LA is modified during auditory fear conditioning in a manner similar to LTP (McKernan and Shinnick-Gallagher, 1997; Rogan et al., 1997). These observations suggest that an LTP-like mechanism in the LA may underlie conditioned fear, which in turn suggests that memory consolidation of auditory fear in the LA and LTP may share a common molecular substrate.

Studies of LTP in the hippocampus have revealed two distinct temporal phases, each characterized by distinct molecular mechanisms. The "early" phase (E-LTP), lasting minutes to hours, does not require protein or RNA synthesis (Frey et al., 1993; Huang et al., 1994; Nguyen and Kandel, 1996). The "late" phase (L-LTP), lasting hours to days, is dependent on RNA and protein synthesis and requires the cAMP-dependent protein kinase (PKA) (Frey et al., 1993; Huang et al., 1994; Nguyen and Kandel, 1996). Application of RNA or protein synthesis inhibitors or inhibitors of PKA to hippocampal slices prevents the induction of

\footnotetext{
Received April 21, 2000; revised June 23, 2000; accepted June 26, 2000.

This research was supported in part by National Institute of Mental Health Grants RO1 MH 46516, KO2 MH00956, R37 MH 39774, and MH 11902-01A1. This work was also supported by a grant from the W. M. Keck Foundation to New York University. We thank Nicole Nadel and Annemieke Schoute for technical assistance. We also thank Karim Nader for helpful comments about this manuscript.

Correspondence should be addressed to Dr. Glenn E. Schafe, Center for Neural Science, New York University, 4 Washington Place, Room 809, New York, NY 10003. E-mail: schafe@cns.nyu.edu.

Copyright (C) 2000 Society for Neuroscience $\quad 0270-6474 / 00 / 200001-05 \$ 15.00 / 0$
}

indicated that immediate post-training infusion of either drug dose-dependently impaired fear memory retention, whereas infusions $6 \mathrm{hr}$ after conditioning had no effect. Additional experiments showed that anisomycin and Rp-cAMPS interfered with long-term memory (LTM), but not short-term memory (STM), of fear and that the effect on LTM was specific to memory consolidation processes rather than to deficits in sensory or performance processes. Findings suggest that the LA is essential for memory consolidation of auditory fear conditioning and that this process is PKA and protein-synthesis dependent.

Key words: fear; amygdala; LTP; memory consolidation; cAMP; protein synthesis

L-LTP in both area CA1 and the dentate gyrus but has little effect on E-LTP (Frey et al., 1993; Nguyen and Kandel, 1996). Furthermore, stimulation that leads to L-LTP transiently activates PKA (Roberson and Sweatt, 1996) and also induces the transcription of cAMP response element (CRE)-mediated genes, an effect that is prevented, along with LTP, by inhibitors of PKA (Impey et al., 1996). These results suggest that PKA is necessary for the longterm protein synthesis-dependent changes that underlie L-LTP and, by implication, hippocampal-dependent memory consolidation (Milner et al., 1998).

The results of several recent studies suggest that PKA activation and RNA and protein synthesis are also involved in fear memory consolidation. For example, blockade of PKA prevents LTP in the LA in vitro (Huang and Kandel, 1998). Furthermore, fear memory consolidation is impaired in transgenic mice that overexpress an inhibitory isoform of PKA (Abel et al., 1997) and also after either systemic or intracerebroventricular administration of inhibitors of protein synthesis or PKA (Bourtchuladze et al., 1998; Schafe et al., 1999). Finally, RNA synthesis inhibition in the amygdala has been shown to impair fear learning (Bailey et al., 1999).

To determine whether PKA activation and protein synthesis in the amygdala are involved in fear memory consolidation, the present series of experiments used direct infusion of inhibitors of PKA and protein synthesis into the LA.

This article is published in The Journal of Neuroscience, Rapid Communications Section, which publishes brief, peer-reviewed papers online, not in print. Rapid Communications are posted online approximately one month earlier than they would appear if printed. They are listed in the Table of Contents of the next open issue of JNeurosci. Cite this article as: JNeurosci, 2000, 20:RC96(1-5). The publication date is the date of posting online at www.jneurosci.org.

http://www.jneurosci.org/cgi/content/full/4501 


\section{MATERIALS AND METHODS}

Subjects. Subjects were adult male Sprague Dawley rats (Hilltop, Scottdale, PA). They were housed individually in plastic Nalgene cages and maintained on a $12 \mathrm{hr}$ light/dark cycle. Food and water were provided freely throughout the experiment.

Surgery. Under Nembutal anesthesia $(45 \mathrm{mg} / \mathrm{kg})$, rats were implanted bilaterally with 22-gauge stainless steel cannulas into the LA. Coordinates, taken from Paxinos and Watson (1986), were -3.0 anteroposterior, \pm 5.3 mediolateral, and $-8.0 \mathrm{~mm}$ dorsoventral. The cannulas were anchored to the skull with stainless steel screws and dental cement. A 28-gauge dummy cannula was inserted into each cannula to prevent clogging. After surgery, rats were given buprenorphine $\mathrm{HCl}(0.2 \mathrm{mg} / \mathrm{kg}$, s.c.) as an analgesic. Rats were given at least $5 \mathrm{~d}$ to recover.

Habituation, conditioning, and microinfusion. On the day before conditioning, rats were habituated for $15 \mathrm{~min}$ to handling and to the conditioning (chamber A) and tone testing (chamber B) chambers [for details of the apparatus, see Schafe et al. (1999)].

For conditioning, rats were placed in chamber A and given a single conditioning trial consisting of a $30 \mathrm{sec}, 5 \mathrm{kHz}, 75 \mathrm{~dB}$ tone that coterminated with a $2.0 \mathrm{~mA}, 1 \mathrm{sec}$ footshock. Immediately after conditioning, rats were inf used with anisomycin $(62.5,6.2$, or $0.62 \mu \mathrm{g}$ per side; $0.5 \mu \mathrm{l})$, Rp-cAMPS $(18,1.8$, or $0.18 \mu \mathrm{g}$ per side; $0.5 \mu \mathrm{l})$, or artificial CSF (ACSF). Although the LA was the main target, the infusions also likely affected the adjacent basal nucleus. We therefore refer to the affected area as the lateral and basal amygdala (LBA).

The highest dose of anisomycin was chosen based on a previous study showing $>90 \%$ suppression of protein synthesis in cortex using this concentration $(125 \mu \mathrm{g} / \mu \mathrm{l})$ (Rosenblum et al., 1993). The highest dose of Rp-cAMPS was chosen based on biochemical evidence indicating that this concentration of Rp-cAMPS effectively blocks PKA activity in vivo (Punch et al., 1997)

Testing. LTM was evaluated the following day. For this test, rats were placed in chamber B and presented with five tones. Rats were videotaped during tone presentations for subsequent behavioral scoring.

Histology. Rats were anesthetized with an overdose of chloral hydrate $(600 \mathrm{mg} / \mathrm{kg}$, i.p.) and perfused with $10 \%$ buffered formalin. Brains were sectioned at $50 \mu \mathrm{m}$ and stained with cresyl violet. Sections were examined with light microscopy for cannula penetration into the LA.

\section{RESULTS}

\section{Intra-LBA infusion of anisomycin or Rp-cAMPS dose- dependently impairs the retention of auditory fear memory}

Figure $1 A-D$ depicts mean auditory fear memory in rats injected with different doses of anisomycin, Rp-cAMPS, or ACSF. $A$ and $C$ depict mean percent freezing scores across each test trial. $B$ and $D$ depict mean percent freezing. For this latter measure, freezing scores were averaged across trials for each rat. For scoring, seconds freezing (of 30) were counted and expressed as a percentage of the total tone presentation time. All data were analyzed using ANOVA and Duncan's $t$ tests.

\section{Anisomycin}

Relative to ACSF controls, rats inf used with the highest dose of anisomycin had substantial memory impairment to the tone $24 \mathrm{hr}$ after conditioning. The ANOVA revealed a significant group effect $\left(F_{(3,24)}=10.49, p<0.01\right)$ but a nonsignificant effect for trials and for the interaction. This same pattern of results is reflected in the mean tone memory scores $\left(F_{(3,24)}=9.32, p<\right.$ $0.01)$, where freezing after the highest dose of anisomycin differed from the ACSF group $(p<0.05)$. Overall, no significant difference was detected between the ACSF and the low or medium dose groups. The amount of freezing demonstrated by rats in the highest dose group $(\sim 30 \%)$ is roughly equivalent to that observed in groups receiving unpaired presentations of tones and shocks in a previous study from our lab using a similar single-trial training protocol (Schafe et al., 1999).

\section{Rp-cAMPS}

The pattern of results for Rp-cAMPS was similar to that of anisomycin. The ANOVA revealed a significant group effect $\left(F_{(3,27)}=11.06, p<0.01\right)$, a significant effect for trials $\left(F_{(4,108)}=\right.$ $3.93, p<0.01)$, and a nonsignificant interaction. The same effect

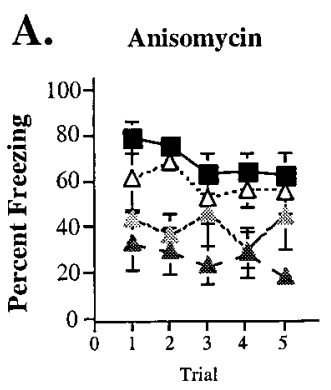

B.

C.
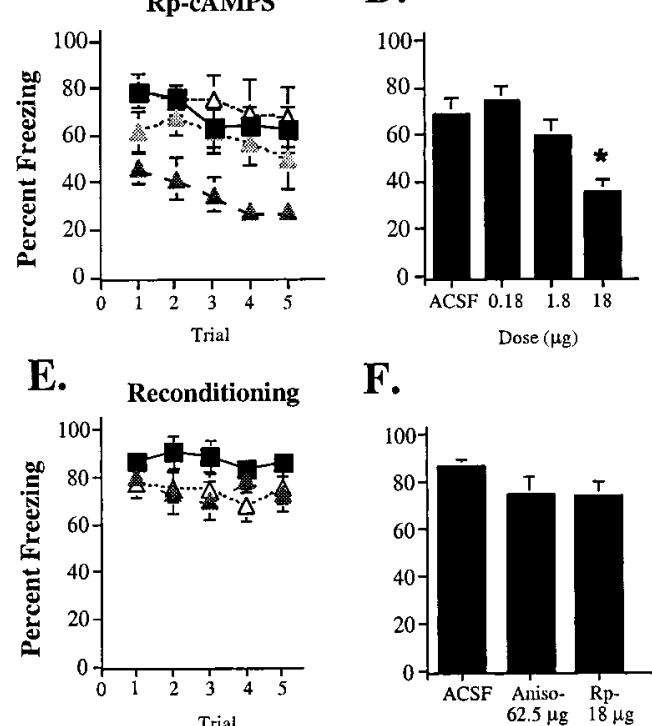

F.

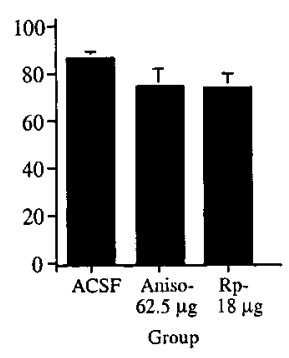

Figure 1. Impaired long-term fear retention after intra-LBA administration of different doses of anisomycin or Rp-cAMPS. $A$, Mean $( \pm \mathrm{SE})$ LTM across all five trials in rats injected with ACSF $(n=12$; black squares $), 0.62 \mu \mathrm{g}(n=4$; white triangles $), 6.25 \mu \mathrm{g}(n=4$; light gray triangles), or $62.5 \mu \mathrm{g}$ anisomycin $(n=9$; dark gray triangles). $B$, Mean $( \pm \mathrm{SE}) \mathrm{LTM}$ averaged across all trials for all anisomycin-treated groups. $C$, Mean $( \pm \mathrm{SE}) \mathrm{LTM}$ across all five trials in rats injected with ACSF $(n=$ 12 ; black squares $), 0.18 \mu \mathrm{g}(n=4$; white triangles $), 1.80 \mu \mathrm{g}(n=4$; light gray triangles), or $18.0 \mu \mathrm{g}$ Rp-cAMPS ( $n=12$; dark gray triangles). $D$, Mean $( \pm \mathrm{SE}) \mathrm{LTM}$ averaged across all trials for all Rp-cAMPS-treated groups. $E$, Mean $( \pm$ SE) LTM across all five trials in rats reconditioned drug-free $\sim 1$ week later. ACSF-, anisomycin-, and Rp-cAMPS-treated groups are represented by black squares, gray triangles, and white triangles, respectively. $F$, Mean ( \pm SE) LTM averaged across all trials for all reconditioned groups. ${ }^{*} p<0.05$ relative to ACSF controls.

was observed for mean tone memory scores $\left(F_{(3,27)}=11.06, p<\right.$ 0.01 ), where freezing after administration of the highest dose of Rp-cAMPS was found to differ from the ACSF group $(p<0.05)$. Overall, no significant differences were detected between the ACSF and the two lower-dose groups.

Furthermore, rats receiving the highest dose of either anisomycin or Rp-cAMPS were able to reacquire fear when they were reconditioned drug-free $\sim 1$ week later (Fig. $1 E, F$ ). The ANOVA revealed no significant effects. Thus, administration of anisomycin or Rp-cAMPS does not appear to result in permanent inability to express fear or to associate tones and shocks, suggesting that amygdala function is not permanently impaired by these compounds.

To determine whether the amnesic effects of anisomycin and Rp-cAMPS were caused by impairment of memory consolidation processes in the LBA, three additional experiments were conducted (Fig. 2). First, inf usion of the highest doses of anisomycin or Rp-cAMPS $24 \mathrm{hr}$ before conditioning had no effect on the 
A.

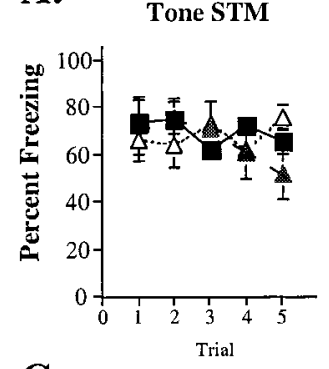

C.

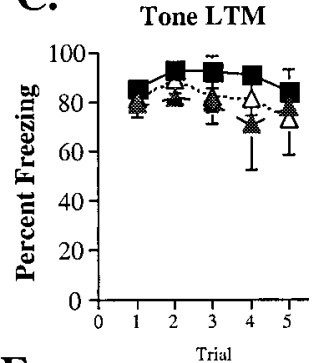

E.

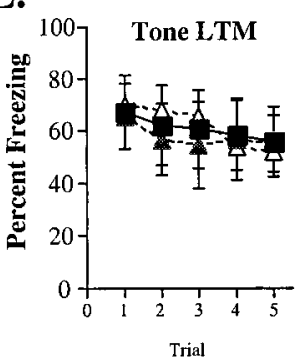

B.

D.
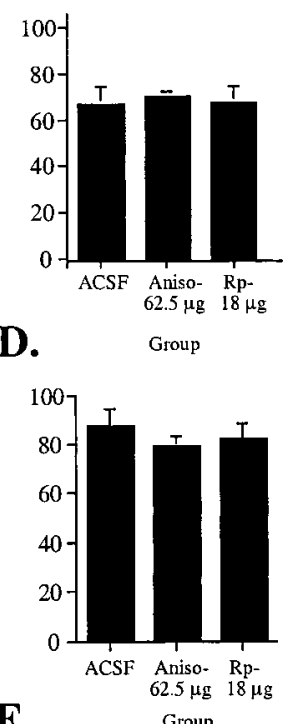

F.

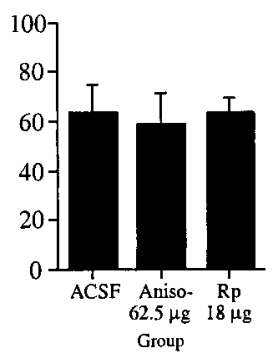

Figure 2. Specificity of the effects of intra-LBA anisomycin and RpcAMPS. $A$, Mean ( \pm SE) STM across all five trials in rats infused with ACSF $(n=6), 18.0 \mu \mathrm{g}$ Rp-cAMPS $(n=6)$, or $62.5 \mu \mathrm{g}$ anisomycin $(n=$ 6) $24 \mathrm{hr}$ before conditioning. $B$, Mean ( \pm SE) STM averaged across all trials for all groups infused $24 \mathrm{hr}$ before conditioning. $C$, Mean $( \pm \mathrm{SE}$ ) LTM across all five trials in rats infused with ACSF $(n=4), 18.0 \mu \mathrm{g}$ Rp-cAMPS $(n=4)$, or $62.5 \mu \mathrm{g}$ anisomycin $(n=4) 2 \mathrm{~mm}$ dorsal to the LBA. $D$, Mean ( \pm SE) LTM averaged across all trials for all dorsal controls. $E$, Mean ( \pm SE) LTM across all five trials in rats infused with ACSF $(n=6), 18.0 \mu \mathrm{g}$ Rp-cAMPS $(n=6)$, or $62.5 \mu \mathrm{g}$ anisomycin $(n=$ $6) 6 \mathrm{hr}$ after conditioning. $B$, Mean $( \pm \mathrm{SE})$ LTM averaged across all trials for all groups infused $6 \mathrm{hr}$ after conditioning. In each figure, ACSF is represented by black squares, anisomycin by gray triangles, and Rp-cAMPS by white triangles.

expression of STM $1 \mathrm{hr}$ after training, which was assessed at approximately the same time as LTM in the previous experiments (Fig. 2A,B). Thus, it is unlikely that the freezing deficits observed in the LTM test are caused by some nonspecific effect of anisomycin or Rp-cAMPS on general activity levels (i.e., hyperactivity) $24 \mathrm{hr}$ after the inf usion. Second, infusion of the highest doses of anisomycin or Rp-cAMPS $2 \mathrm{~mm}$ above the LBA had no effect on fear retention (Fig. 2C,D). Thus, the behavioral effects of each drug cannot be attributed to diffusion into the striatum or adjacent cortical areas dorsal to the rhinal fissure. Third, consistent with the time-limited role of memory consolidation processes (Davis and Squire, 1984) and with a recent paper showing no effect of systemic or intracerebroventricular infusions of anisomycin or Rp-cAMPS 6 hr after training (Bourtchuladze et al., 1998), intra-LBA infusions of either drug $6 \mathrm{hr}$ after training had no effect on fear retention (Fig. $2 E, F$ ). Collectively, findings strongly favor the conclusion that anisomycin and Rp-cAMPS impair fear memory retention by blocking memory consolidation processes.

A.

Tone STM

B.
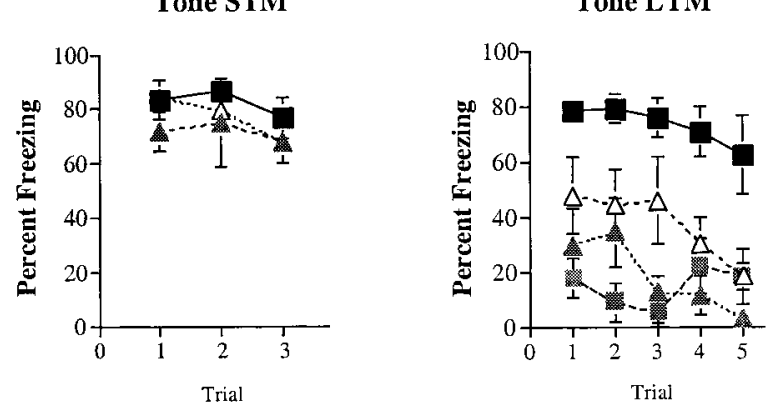

C.

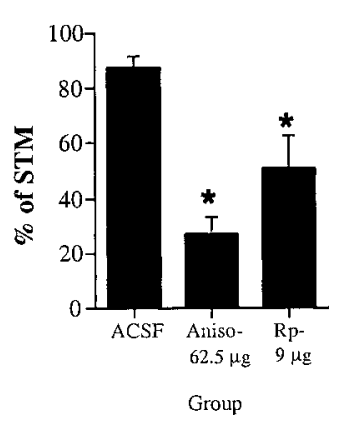

Figure 3. Impaired LTM, but not STM, after intra-LBA infusion of anisomycin or Rp-cAMPS. $A$, Mean $( \pm$ SE) STM across all three trials in rats infused with ACSF $(n=5), 62.5 \mu \mathrm{g}$ anisomycin $(n=5)$, or $9 \mu \mathrm{g}$ Rp-cAMPS $(n=5)$. $B$, Mean ( \pm SE) LTM across all five tone test trials in rats injected with ACSF, anisomycin, or Rp-cAMPS. Rats injected with anisomycin both immediately after training and $4 \mathrm{hr}$ before LTM testing $(n=6)$ are represented by gray squares. $C$, Mean $( \pm \mathrm{SE})$ percent of STM for rats injected with either ACSF, anisomycin, or Rp-cAMPS. * $p<$ 0.05 relative to ACSF. In each figure, ACSF is represented by black squares, anisomycin by gray triangles, and Rp-cAMPS by white triangles.

\section{Intra-LBA infusion of anisomycin or Rp-cAMPS impairs LTM, but not STM, of auditory fear conditioning}

In the first series of experiments, auditory fear memory was assessed $24 \mathrm{hr}$ after conditioning. To more directly evaluate the possibility that anisomycin and Rp-cAMPS produced their effects on fear memory by interfering with memory consolidation processes, the final experiment evaluated both STM and LTM in the same animals.

Before performing the experiment, pilot studies were conducted to determine the optimal time point to assay for STM of auditory fear using our one-trial conditioning and post-training infusion paradigm. We found that administration of the highest dose of anisomycin $(62.5 \mu \mathrm{g}$ per side) produced what appeared to be performance deficits (i.e., rats were unable to freeze) in auditory fear at $1 \mathrm{hr}$, but not at $4 \mathrm{hr}$, after conditioning and infusion, presumably because of temporary disruption of sensory transmission in the amygdala. Furthermore, the highest dose of Rp-cAMPS (18 $\mu \mathrm{g})$ was observed to impair auditory fear memory at both 1 and $4 \mathrm{hr}$ after infusion. We therefore reduced the dose of Rp-cAMPS to $9 \mu \mathrm{g}$ per side, which was observed to be without significant effect on auditory STM $4 \mathrm{hr}$ after training and drug infusion.

Rats were given one-trial auditory fear conditioning and infused immediately thereafter as in the initial experiments. Four hours later, rats were placed in chamber $B$ and given three exposures to the tone. Approximately $24 \mathrm{hr}$ later, rats were evaluated for LTM to the tone as in the previous experiments.

Percent freezing across each trial for tone STM and LTM scores is presented in Figure 3, $A$ and $B$, respectively, and mean relative memory scores for each group are presented in Figure 
A.

Figure 4. Cannula placements. $A$, Cannula tip placements from rats infused with ACSF (black squares), $0.62 \mu \mathrm{g}$ anisomycin (white triangles), $6.25 \mu \mathrm{g}$ anisomycin (light gray triangles), or $62.5 \mu \mathrm{g}$ anisomycin (dark gray triangles). B, Cannula tip placements from rats infused with ACSF (black squares), $0.18 \mu \mathrm{g}$ Rp-cAMPS (white triangles), $1.80 \mu \mathrm{g}$ Rp-cAMPS (light gray triangles), or $18.0 \mu \mathrm{g} \mathrm{Rp-cAMPS} \mathrm{(dark} \mathrm{gray} \mathrm{trian-}$ gles). Adapted from Paxinos and Watson (1986).

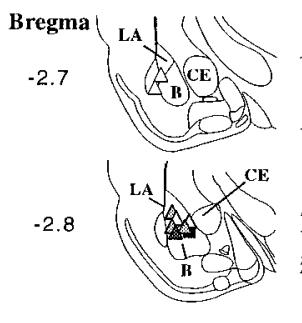

$-3.3$

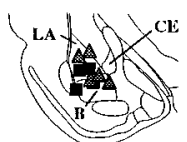

$-3.8$

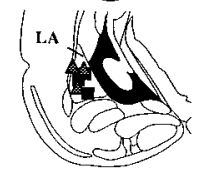

B.
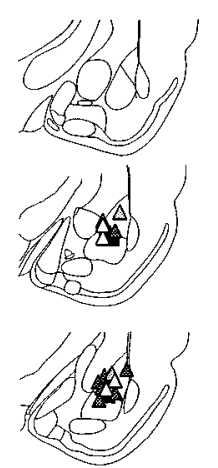

Bregma ! $-2.7$
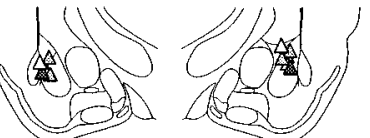

$-2.8$
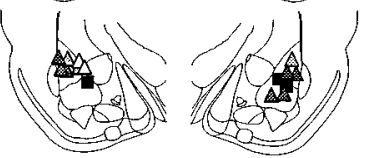

$-3.3$
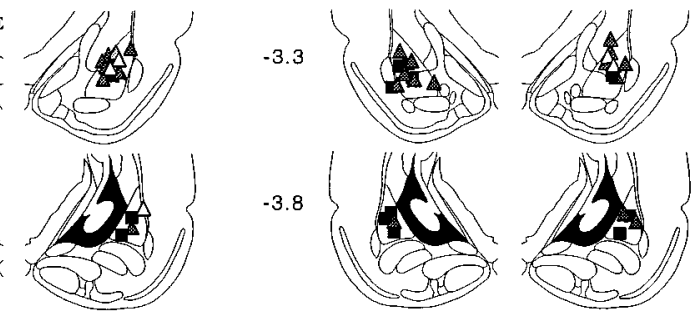

3C. For this latter measure, LTM scores were calculated as a percentage of STM scores for each rat. Baseline freezing during the $30 \mathrm{sec}$ period just before the first tone presentation in the STM test was negligible and was not found to differ between groups (ACSF: $6.4 \pm 3.3 \%$; anisomycin: $4.6 \pm 3.8 \%$; Rp-cAMPS: $7.8 \pm 4.4 \%)$. Thus, fear did not generalize from chamber A to chamber B.

The ANOVA for STM scores revealed a nonsignificant group effect, a nonsignificant effect of trials, and a nonsignificant interaction. The ANOVA for LTM scores, however, showed a significant group effect $\left(F_{(2,12)}=16.60, p<0.01\right)$, a significant effect of trials $\left(F_{(4,48)}=5.39, p<0.01\right)$, and a nonsignificant interaction. Overall, this same pattern of results is reflected in the relative memory scores $\left(F_{(2,12)}=11.10, p<0.01\right)$, where both the anisomycin- and Rp-cAMPS-inf used groups showed significant memory impairment relative to ACSF controls $(p<0.05)$. No significant difference was detected between anisomycin and RpcAMPS groups. Thus, immediate post-training infusion of anisomycin or Rp-cAMPS into LBA impairs LTM of auditory fear conditioning, whereas it leaves STM intact.

Finally, to rule out possible state-dependent influences that may have contributed to intact fear memory at $4 \mathrm{hr}$, we took an additional group of rats and infused them with anisomycin both immediately after training and $4 \mathrm{hr}$ before LTM testing on the following day. If STM $4 \mathrm{hr}$ after training was caused by statedependent influences, then, by implication, LTM in these rats should be intact. Findings indicated that it was not (Fig. 3B). An ANOVA comparing LTM scores between anisomycin-treated rats tested drug-free and those tested under the influence of anisomycin showed no significant differences. Thus, it cannot be concluded that impaired LTM (or intact STM) was caused by state-dependent drug effects.

\section{Histology}

Cannula placements are shown in Figure 4, $A$ and $B$. Cannula tips were observed throughout the LBA. Only rats with cannula tips at or within the boundaries of LBA were included in the data analysis. Results of cannula tip analysis are shown only for the first two experiments in which rats were injected with different doses of anisomycin or Rp-cAMPS.

\section{DISCUSSION}

Evidence has suggested that the LBA is the site of the plastic changes underlying auditory fear conditioning. In support of this hypothesis, either permanent lesions or reversible functional inactivation of the LBA has been shown to eliminate auditory fear conditioning (LeDoux et al., 1990; Wilensky et al., 2000). Furthermore, cells in the LA have been shown to respond to both auditory and somatosensory stimuli (Romanski et al., 1993) and to receive projections from the auditory thalamus and cortex (LeDoux et al., 1991). Importantly, LTP has been demonstrated in each of these pathways (Chapman et al., 1990; Rogan and LeDoux, 1995), and auditory fear conditioning has been shown to modify neural activity in the LA in a manner similar to LTP induction (McKernan and Shinnick-Gallagher, 1997; Rogan et al., 1997). These observations suggest that an LTP-like mechanism underlies fear acquisition in the LBA and thus that fear memory consolidation in the LBA and LTP may be characterized by common molecular mechanisms. In support of this hypothesis, findings of the present experiments indicate that auditory fear memory consolidation is dose-dependently disrupted by intraLBA administration of inhibitors of protein synthesis and PKA. This pattern of findings is consistent with the LTP literature in which pharmacological disruption of both protein synthesis and PKA has been shown to selectively block hippocampal L-LTP, whereas it has little effect on E-LTP (Frey et al., 1993; Nguyen and Kandel, 1996). It is also consistent with a recent study demonstrating a role for PKA in amygdala LTP (Huang and Kandel, 1998). Collectively, results suggest that fear memory consolidation in the LA and LTP may share a common molecular substrate.

Several recent studies using either transgenic methods or systemic or intracerebroventricular administration of drugs have implicated protein synthesis or PKA, or both, in fear memory consolidation (Abel et al., 1997; Bourtchuladze et al., 1998; Schafe et al., 1999). In contrast to these previous studies, the present study evaluated the role of protein synthesis and PKA specifically in the LBA. Intra-LBA administration of inhibitors of protein synthesis or PKA dose-dependently disrupted LTM of Pavlovian fear conditioning when given immediately after, but not $6 \mathrm{hr}$ after, conditioning. Furthermore, controls suggested that the effect was localized to the amygdala and specific to memory consolidation rather than to sensory or performance processes. When considered together with the results of a recent report which showed that RNA synthesis inhibition in the LBA impairs fear memory (Bailey et al., 1999), the accumulating evidence favors the view that fear memory consolidation requires PKAdependent gene expression and protein synthesis in the amygdala.

Although the present study did not evaluate the full time course of the effects of administration of anisomycin and RpcAMPS on fear memory, it is of interest that STM of auditory 
fear conditioning was intact $4 \mathrm{hr}$ after training and drug infusion but resistant to disruption at $6 \mathrm{hr}$. This finding stands in contrast to the time course analysis of a previous report showing that $\alpha / \delta$ CREB mutant mice have impaired memory for auditory fear conditioning $2 \mathrm{hr}$ after training (Bourtchuladze et al., 1994). Consistent with our results, however, a recent study reported that fear memory in mice is disrupted after systemic or intracerebroventricular administration of anisomycin or Rp-cAMPS either immediately or $4 \mathrm{hr}$ after single-trial training but not at $6 \mathrm{hr}$ (Bourtchuladze et al., 1998). These two critical periods are thought to represent multiple waves of gene expression necessary for LTM formation (Bourtchuladze et al., 1998). The full time course of PKA/protein synthesis involvement in fear memory consolidation is an important question that awaits further study.

Although the experiments presented in this paper used intraLBA infusions of drugs, it should be noted that it remains possible that our inf usions affected not only the LBA but also the nearby central nucleus of amygdala (CE). Thus, although dorsal controls suggest that our behavioral effects cannot be attributed to diffusion into striatal or cortical structures, at the present time it is not possible to ascertain whether the $\mathrm{CE}$ also contributes to consolidation processes. Furthermore, because PKA and MAP kinase have recently been shown to interact in complex ways during signal transduction (Impey et al., 1998; Roberson et al., 1999), and because MAP kinase has also been shown to be involved in fear memory (Atkins et al., 1998; Schafe et al., 1999), the possibility remains that our infusions of Rp-cAMPS influenced fear memory consolidation in the LBA by acting on this signaling pathway. Experiments are currently underway in our laboratory to address these important questions.

The results of the present study clearly suggest that a protein synthesis and PKA-dependent process underlies fear memory consolidation in the amygdala. Because LTP in both the hippocampus (Frey et al., 1993; Huang et al., 1994; Nguyen and Kandel, 1996) and the amygdala (Huang and Kandel, 1998) has been characterized by similar molecular processes, this provides further evidence that is consistent with the hypothesis that an LTP-like mechanism underlies fear acquisition and memory formation in the LBA.

\section{REFERENCES}

Abel T, Nguyen PV, Barad M, Deuel TAS, Kandel ER, Bourtchuladze R (1997) Genetic demonstration of a role for PKA in the late phase of LTP and in hippocampus-based long-term memory. Cell 88:615-626.

Atkins CM, Selcher JC, Petraitis JJ, Trzaskos JM, Sweatt JD (1998) The MAPK cascade is required for mammalian associative learning. Nat Neurosci 1:602-610.

Bailey DJ, Kim JJ, Sun W, Thompson RF, Helmstetter FJ (1999) Acquisition of fear conditioning in rats requires the synthesis of mRNA in the amygdala. Behav Neurosci 113:276-282.

Bourtchuladze R, Frenguelli B, Blendy J, Cioff D, Schutz G, Silva AJ (1994) Deficient long-term memory in mice with a targeted mutation of the cAMP-responsive element-binding protein. Cell 79:59-68.

Bourtchuladze R, Abel T, Berman N, Gordon R, Lapidus K, Kandel ER (1998) Different training procedures recruit either one or two critical periods for contextual memory consolidation, each of which requires protein synthesis and PKA. Learning Memory 5:365-374.

Chapman PF, Kairiss EW, Keenan CL, Brown TH (1990) Long-term synaptic potentiation in the amygdala. Synapse 6:271-278.

Clugnet M, LeDoux JE (1990) Synaptic plasticity in fear conditioning circuits: induction of LTP in the lateral nucleus of the amygdala by stimulation of the medial geniculate body. J Neurosci 10:2818-2824.
Davis HP, Squire LR (1984) Protein synthesis and memory. Psychol Bull 96:518-559.

Davis M (1997) Neurobiology of fear responses: the role of the amygdala. J Neuropsychiat Clin Neurosci 9:382-402.

Fanselow MS, LeDoux JE (1999) Why we think plasticity underlying Pavlovian fear conditioning occurs in the basolateral amygdala. Neuron 23:229-232.

Frey U, Huang YY, Kandel ER 1993 Effects of cAMP stimulate a late stage of LTP in hippocampal CA1 neurons. Science 260:1661-1664.

Huang Y, Li X, Kandel ER (1994) cAMP contributes to mossy fiber LTP initiating both a covalently mediated early phase and macromolecular synthesis-dependent phase late phase. Cell 79:69-79.

Huang YY, Kandel ER (1998) Postsynaptic induction and PKAdependent expression of LTP in the lateral amygdala. Neuron 21:169-178.

Impey S, Mark M, Villacres EC, Poser S, Chavkin C, Storm DR (1996) Induction of CRE-mediated gene expression by stimuli that generate long-lasting LTP in area CA1 of the hippocampus. Neuron 16:973-982.

Impey S, Obrietan K, Wong S, Poser S, Yano S, Wayman G, Deloulme JC, Chan G, Storm DR (1998) Cross talk between ERK and PKA is required for $\mathrm{Ca}^{2+}$ stimulation of CREB-dependent transcription and ERK nuclear translocation. Neuron 21:869-883.

LeDoux JE, Cicchetti P, Xagorias A, Romanski LM (1990) The lateral amygdaloid nucleus: sensory interface of the amygdala in fear conditioning. J Neurosci 10:1062-1069.

LeDoux JE, Farb CR, Romanski LM (1991) Overlapping projections to the amygdala and striatum from auditory processing areas of the thalamus and cortex. Neurosci Lett 134:139-144.

LeDoux JE (2000) Emotion circuits in the brain. Annu Rev Neurosci 23:155-184.

McKernan MG, Shinnick-Gallagher P (1997) Fear conditioning induces a lasting potentiation of synaptic currents in vitro. Nature 390:607-611.

Milner B, Squire LR, Kandel ER (1998) Cognitive neuroscience and the study of memory. Neuron 20:445-468.

Nguyen PV, Kandel ER (1996) A macromolecular synthesis-dependent late phase of long-term potentiation requiring cAMP in the medial perforant pathway of rat hippocampal slices. J Neurosci 16:3189-3198.

Paxinos G, Watson C (1986) The rat brain in stereotaxic coordinates, Ed 2. San Diego: Academic.

Punch LJ, Self DW, Nestler EJ, Taylor JR (1997) Opposite modulation of opiate withdrawal behaviors on microinfusion of a protein kinase A inhibitor versus activator into the locus coeruleus or periaqueductal gray. J Neurosci 17:8520-8527.

Roberson ED, Sweatt JD (1996) Transient activation of cyclic AMPdependent protein kinase during hippocampal long-term potentiation. J Biol Chem 271:30436-30441.

Roberson ED, English JD, Adams JP, Selcher JC, Kondratick C, Sweatt JD (1999) The mitogen-activated protein kinase cascade couples PKA and PKC to cAMP response element binding protein phosphorylation in area CA1 of hippocampus. J Neurosci 19:4337-4348.

Rogan MT, LeDoux JE (1995) LTP is accompanied by commensurate enhancement of auditory-evoked responses in a fear conditioning circuit. Neuron 15:127-136.

Rogan MT, Staubli UV, LeDoux JE (1997) Fear conditioning induces associative long-term potentiation in the amygdala. Nature 390:604-607.

Romanski LM, Clugnet M, Bordi F, LeDoux JE (1993) Somatosensory and auditory convergence in the lateral nucleus of the amygdala. Behav Neurosci 107:444-450.

Rosenblum K, Meiri N, Dudai Y (1993) Taste memory: the role of protein synthesis in gustatory cortex. Behav Neural Biol 59:50-56.

Schafe GE, Nadel NV, Sullivan GM, Harris A, LeDoux JE (1999) Memory consolidation for contextual and auditory fear conditioning is dependent on protein synthesis, PKA, and MAP kinase activity. Learning Memory 6:97-110.

Weisskopf MG, Bauer EP, LeDoux JE (1999) L-type voltage-gated calcium channels mediate NMDA-independent associative long-term potentiation at thalamic input synapses to the amygdala. J Neurosci 19:10512-10519.

Wilensky AE, Schafe GE, LeDoux JE 2000 The amygdala modulates memory consolidation of fear-motivated inhibitory avoidance learning, but not classical fear conditioning. J Neurosci, in press. 